\title{
Ground Water Pollution around the Northern Part of Yokkaichi City
}

\author{
Masaaki Takahashi, Yukimasa Takemoto, Kayoko Awaya, Mikihiro Ioka and Peng Guo \\ Faculty of Environmental and Information Sciences, Yokkaichi University, 1200 Kayo-cho, Yokkaichi, Mie 512-8512, Japan
}

\begin{abstract}
Water pollution in the ground water has been widely found in the northern part of Yokkaichi city. The biggest illegal disposal site of industrial waste in central Japan was found in this area. In order to identify the source of this pollution, the authors have investigated the ground water pollution around this illegal landfill site. Investigation of well and the seepage water was carried out at 26 observation sites, and the concentrations of the following parameters such as $\mathrm{pH}, \mathrm{EC}, \mathrm{COD}, \mathrm{T}-\mathrm{N}, \mathrm{T}-\mathrm{P}, \mathrm{D}-\mathrm{Fe}, \mathrm{D}-\mathrm{Mn}$, arsenic and 1, 4-dioxane were analyzed. Pollution of COD, T-P, T-N, D-Fe, D-Mn, arsenic and 1, 4-dioxane was found. However, relation between these pollutants and the illegal disposal is not apparent, and needs further investigation.
\end{abstract}

Key words: Pollution, illegal disposal, ground water.

\section{Introduction}

Yokkaichi city is situated in central Japan, about 30 $\mathrm{km}$ away from Nagoya city, and has the Suzuka mountain chain (almost 1,000 m height) $15-20 \mathrm{~km}$ west side, and has Ise bay on its east side. The city is well known as the air pollution caused by the Yokkaichi petroleum complex.

Half of this area is by an occupied diluvial deposit hill (about 40-70 m altitude) and the latter half (mainly the east side) is an alluvium plain, and many springs are found, clean water flowed out from them in earlier days.

The deposit hills are covered by broad leafed forest, and in the alluvium plain, there are rice fields and an old residential area.

About 40 years ago, the interchange of Higashi Meihan Highway was constructed nearby, due to the convenience pertaining to transport/accessibility conditions, many transporting facilities, warehouses, residences and also, many landfill site of industrial waste or municipal waste have been disorderly constructed. Recently, Toshiba Corporation

Corresponding author: Masaaki Takahasi, professor, research field: environmental technology. E-mail: machaaki@amigo.ne.jp. constructed a large semiconductor factory on the hill.

In 1981, Kawagoe Kenzai Co. constructed a land fill site. This company violated the approved legal emission limits twice, and has since then lost the right to use the land fill site based on a law court's decision in 1994. However, even 10 years after the ban, these illegally disposed wastes have been left in the site untreated, and the pollution is thought to be spreading [1].

The disposal site was constructed on a hill about 50-70 m above sea level, the width of an area $300 \mathrm{~m} \times$ $300 \mathrm{~m}$ (about 100,000 $\mathrm{m}^{2}$ ), and the amount of disposed waste reached about 2.86 million tons (the largest in Japan).

Recently, wide spread water pollution of ground water has been found in and around the landfill site [2-5] and many toxic substances (arsenic, $\mathrm{Pb}$ and 1, 4-dioxane) are detected in the ground water [6].

However, few investigations of the surrounding area have been carried out until now. In order to identify the influence of disposal on the ground water, the authors have carried out the survey in the vicinity of the disposal site within $5 \mathrm{~km}$ of it. 


\section{Method}

\subsection{Survey Date and Feature of the Site}

\subsubsection{Date}

Survey was carried out in 2006-2011.

\subsubsection{Survey Sites}

Survey was carried out at 26 sites, the area belong to Tomida, Mochifuku, Oyachi, Shimonomiya, Heizu, Yamano-issiki and Tarusaka district, shown in Table 1 and Fig. 1.

\subsection{Parameter and Method}

Parameters and analytical methods used in this survey are as follows:

$\mathrm{pH}$ : glass-electrode;

EC: platinum electrode;

COD: acidic potassium permanganate method;

$\mathrm{T}-\mathrm{N}$ : ultra violet spectrophotometric method;
T-P: molybdenum blue method;

1, 4-Dioxane: LC-MS method;

As: ICP-MS method;

Dissolved iron (D-Fe): simple method (Kyouritsu Rika Co. Pack test);

Dissolved manganese (D-Mn): simple method (Kyouritsu Rika Co. Pack test).

\section{Results and Discussions}

The analytical result of the ground water is shown in Tables 1-3.

An offensive odor similar to that of $\mathrm{H}_{2} \mathrm{~S}$ was found in the ground water at half of the investigated points as shown in Fig. 1. Such odor is considered which is usually associated with an anaerobic state in the ground water.

$\mathrm{pH}$ of the water was in the range of 5.9-8.0, these values are within the Japanese environmental quality standard.

Table 1 Features of the survey sites.

\begin{tabular}{|c|c|c|c|}
\hline Site & Type of the water source and situation (district) & Distance from the boundary (m) & Well depth (m) \\
\hline St1 & Leaching water (Oyachi) & 500 & - \\
\hline St2 & Deep well for irrigation (Tarusaka) & 800 & 200 \\
\hline St3 & Artesian water from well (Heizu) & 1,000 & 200 \\
\hline St4 & Artesian water from well (Nakamura) & 1,800 & - \\
\hline St5 & Spring (Shimonomiya) & 2,000 & - \\
\hline St6 & Artesian water from well (Yamano-issiki) & 1,500 & 200 \\
\hline St7 & Deep well for irrigation (Yamano-issiki) & 2,000 & 200 \\
\hline St8 & Deep well for irrigation (Yamano-issiki) & 2,000 & 200 \\
\hline St9 & Deep well for irrigation (Yamano-issiki) & 2,500 & 200 \\
\hline St10 & Well (Oyachi) & 1,100 & 5 \\
\hline St12 & Leaching water from retaining wall (Heizu) & 500 & - \\
\hline St13 & Leaching water (Oyachi) & 1,300 & - \\
\hline St14 & Well (Ikaruga) & 1,500 & 3 \\
\hline St15 & Leaching water (Mochifuku) & 1,600 & - \\
\hline St16 & Leaching water (Mochifuku) & 1,700 & - \\
\hline St17 & Well (Mochifuku) & 3,000 & $<10$ \\
\hline St18 & Well (Tomida) & 3,000 & $<10$ \\
\hline St19 & Well (Oyachi) & 1,300 & 30 \\
\hline St20 & Well (Sakabe) & 3,000 & 10 \\
\hline St21 & Well (Heizu) & 1,000 & 4 \\
\hline St22 & Well (Oyachi) & 1,100 & $<10$ \\
\hline St23 & Well (Kayo) & 1,700 & 60 \\
\hline St51 & Leaching water, near disposal site (Heizu) & 100 & - \\
\hline St52 & Leaching water near disposal site (Heizu) & 100 & - \\
\hline St54 & Leaching water near disposal site (Heizu) & 200 & - \\
\hline St55 & Leaching water from disposal site (Oyachi) & 0 & - \\
\hline
\end{tabular}



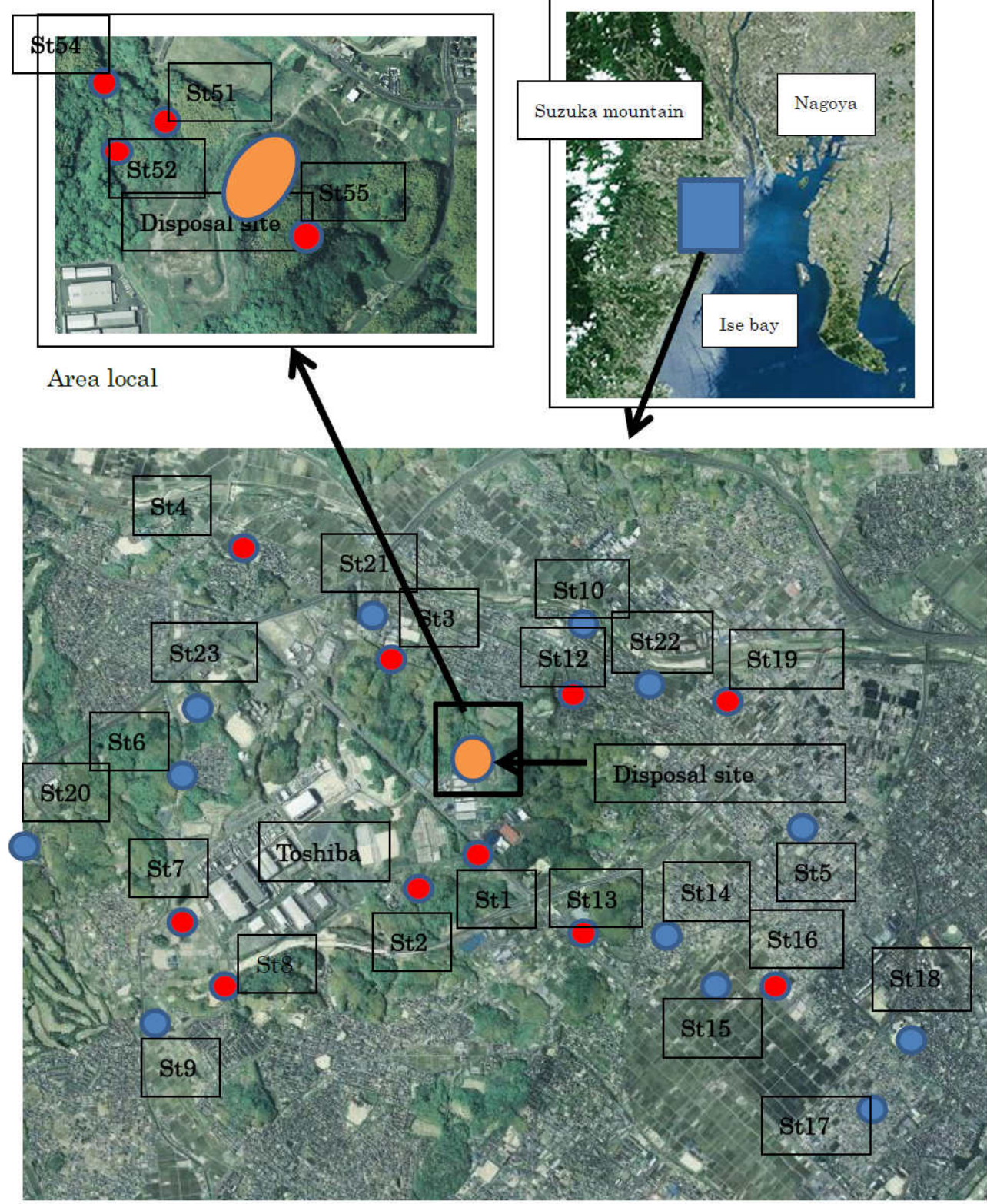

Area overall

Fig. 1 Survey area (Yahoo aerial photograph [7]).

Survey site in which offensive odor was found.

Survey site in which offensive odor was not found.

High value of EC has detected near the landfill site (St52, St54, St55).

The concentrations of COD are very high levels in near landfill site (St51, St52, St54, St55), and high concentration of T-N was also found at St55.

From Mie prefectural investigation data, very high values of EC, T-N, COD was found in residue water of the landfill site [8], therefore, this pollution is

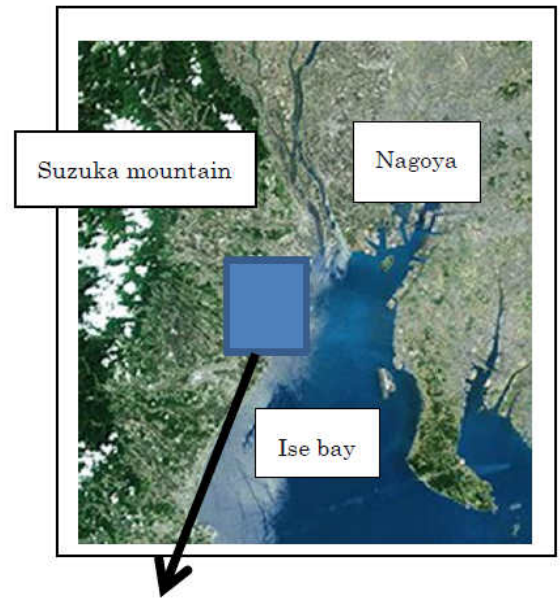

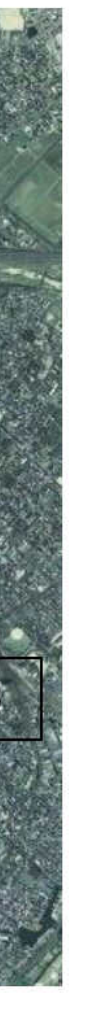


A high concentrations of dissolved iron (D-Fe), dissolved manganese (D-Mn), were found widely in the ground water of the east side of the landfill site shown in Fig. 2. However, low concentration of D-Fe was detected in St51 and St54 where is regarded as an influenced area of the landfill site, and significant value of D-Fe was detected in remote area (St16).

High value of arsenic pollution which reaches the Japan environmental quality standard was found in the water within $2 \mathrm{~km}$ away from disposal site (St3, St8, St12) and also Tomida area (St16, St17, St18) [9] shown in Fig. 3, however, in waters in near landfill site (St51, St52, St54, St55) no arsenic has been detected.

In previous paper [10], simulation of the ground water movement and ion compositional analysis (component: $\mathrm{Cl}^{-}, \mathrm{NO}_{3}{ }^{-}, \mathrm{NH}_{4}^{+}, \mathrm{Mg}^{2+}, \mathrm{Ca}^{2+}, \mathrm{D}-\mathrm{Fe}$ ) on ground water of the survey area was carried out. The result showed that the ionic composition of the water of St54, St55 and St7, St8 are different from each other, and these waters are thought to be not directly related.

In other report [11], the correlation between ground water distribution in the landfill site and amount of the eluted arsenic from the disposal soil was not coincident.

These analytical results suggest the pollution of T-P, arsenic, D-Fe, D-Mn are not caused by direct influence of the landfill site, and another cause should be considered.

The 1, 4-dioxane was detected near the disposal site (St1, St54, St55) shown in Fig. 4 [12], these pollutants are regarded as leachate from the dumping site because high concentrations of 1, 4 dioxane (0.4-2.4 mg/L [3]) were found in the landfill site.

\section{Table 2 Water quality in St1 to St9.}

\begin{tabular}{llllllllll}
\hline Parameter & St1 & St2 & St3 & St4 & St5 & St6 & St7 & St8 & St9 \\
\hline Temp. $\left({ }^{\circ} \mathrm{C}\right)$ & 16 & 18 & 22 & 22 & 15 & 17 & 19 & 24 & 17 \\
pH & 6.8 & 6.7 & 8.0 & 7.8 & 6.1 & 6.0 & 6.5 & 7.3 & 6.4 \\
EC $(\mathrm{mS} / \mathrm{cm})$ & 0.29 & 0.21 & 0.19 & 0.12 & 0.15 & 0.14 & 0.14 & 0.15 & 0.14 \\
COD $(\mathrm{mg} / \mathrm{L})$ & 3.2 & 1.0 & 2.1 & 0.7 & 1.3 & 1.63 & 0.9 & 2.0 & $<0.5$ \\
T-N (mg/L) & 1.4 & 1.2 & 0.70 & 0.49 & 2.1 & 0.47 & 0.83 & 1.2 & 1.9 \\
T-P (mg/L) & 0.03 & 0.31 & 0.58 & 0.33 & 0.06 & 0.06 & 0.23 & 1.5 & 0.02 \\
D-Fe (mg/L) & 10 & 8 & $<0.05$ & $<0.05$ & 0.2 & 4 & 5 & 0.8 & 0.05 \\
D-Mn (mg/L) & 3 & 0.8 & $<0.25$ & $<0.25$ & $<0.25$ & $<0.25$ & 1 & $<0.25$ & $<0.25$ \\
As $(\mathrm{mg} / \mathrm{L})$ & 0.005 & 0.002 & 0.012 & - & - & - & $<0.001$ & 0.014 & - \\
Odor & Found & Found & Found & Found & ND* & ND* & Found & Found & ND* \\
Survey date & April 17, & April 17, & April 17, & April 17, & April 17, & April 17, & April 17, & April 17, & April 17, \\
\hline
\end{tabular}

*ND means "not detected".

Table 3 Water quality in St10 to St19.

\begin{tabular}{llllllllll}
\hline Parameter & St10 & St12 & St13 & St14 & St15 & St16 & St17 & St18 & St19 \\
\hline Temp. $\left({ }^{\circ} \mathrm{C}\right)$ & 15 & - & - & 18 & 18 & 15 & 13 & 14 & 16 \\
pH & 6.2 & 6.9 & 6.8 & 5.9 & 5.9 & 6.6 & 6.7 & 7.9 & 6.5 \\
EC $(\mathrm{mS} / \mathrm{cm})$ & 0.16 & 0.42 & 0.26 & 0.19 & 0.19 & 0.24 & 0.12 & 0.34 & 0.13 \\
COD $(\mathrm{mg} / \mathrm{L})$ & 0.5 & 2.7 & 2.0 & $<0.5$ & & 2.7 & 0.8 & 0.7 & 0.9 \\
T-N (mg/L) & 2.4 & 1.2 & 2.5 & 5.9 & & 2.0 & 3.7 & 2.3 & 0.7 \\
T-P (mg/L) & 0.15 & 0.17 & 0.05 & 0.07 & & 0.24 & 0.82 & 0.96 & 0.06 \\
D-Fe (mg/L) & $<0.05$ & 7 & 10 & $<0.05$ & $<0.05$ & 10 & $<0.05$ & $<0.05$ & 1.5 \\
D-Mn (mg/L) & $<0.25$ & 1 & 1 & $<0.25$ & $<0.25$ & 0.7 & $<0.25$ & $<0.25$ & $<0.2$ \\
As (mg/L) & - & 0.020 & $<0.001$ & - & - & 0.01 & 0.006 & 0.006 & $<0.001$ \\
Odor & ND* & Found & Found & ND* & ND* & Found & ND* & ND* & Found \\
Date & April 17, & \multirow{2}{*}{ May 9, 2011 } & April 17, & April 17, & April 17, & April 17, & April 17, & April 17, & April 17, \\
\hline
\end{tabular}

*ND means "not detected". 
Table 4 Water qualities in St18 to St55.

\begin{tabular}{lllllllll}
\hline Parameter & St20 & St21 & St22 & St23 & St51 & St52 & St54 & St55 \\
\hline Temp. $\left({ }^{\circ} \mathrm{C}\right)$ & - & 18 & 21 & 16 & - & - & - & - \\
pH & 6.2 & 6.0 & 6.3 & 5.6 & 6.8 & 6.5 & 7.3 & 7.9 \\
EC (mS/cm) & 0.11 & 0.11 & 0.12 & 0.16 & 0.60 & 0.94 & 2.4 & 3.9 \\
COD (mg/L) & $<0.5$ & 1.2 & 3.4 & 0.5 & 16 & 23 & 14 & 64 \\
T-N (mg/L) & 1.5 & 0.88 & 0.36 & 0.21 & 6.4 & 3.3 & 2.0 & 86 \\
T-P (mg/L) & 0.02 & 0.05 & 0.58 & 0.03 & 0.63 & 0.45 & 0.25 & 0.35 \\
As (mg/L) & - & - & - & - & $<0.001$ & - & - & $<0.001$ \\
D-Fe (mg/L) & $<0.25$ & $<0.05$ & $<0.05$ & 0.2 & 1 & 8 & 0.3 & 10 \\
D-Mn (mg/L) & $<0.25$ & $<0.25$ & $<0.25$ & $<0.25$ & $<0.25$ & 2 & 5 & $<0.25$ \\
Odor & ND* & ND* & ND* & ND* & Found & Found & Found & Found \\
Date & April 17, 2007 & August 2, & August 2, & August 2, & May 9, 2011 & May 9, 2011 & May 9, 2011 & May 9, 2011 \\
\hline
\end{tabular}

*ND means “not detected”.
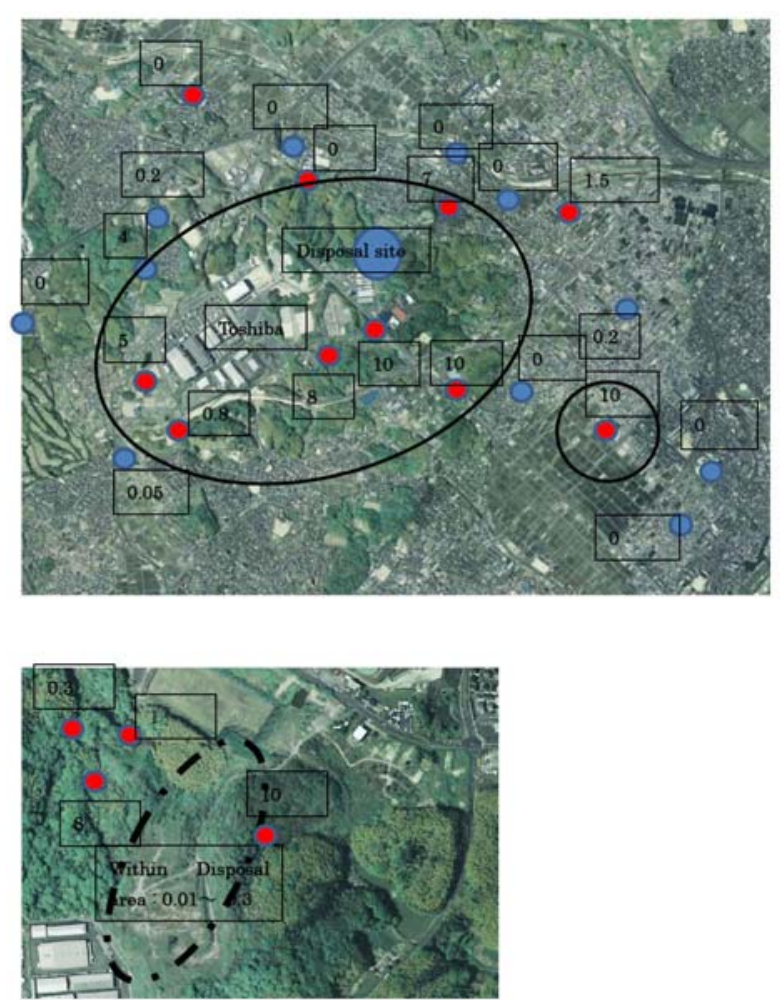

Fig. 2 D-Fe in the water of the investigated area.

Unit: mg/L.

Toshiba Corporation is using much industrial water, and regarded as one of the sources of the pollution, however, waste water from them is discharged into the river (near St7) directly after water treatment, and its influence is regarded as low.

Domestic waste water in this area is mostly flowing to a municipal water treatment facility, so its influence is considered small.
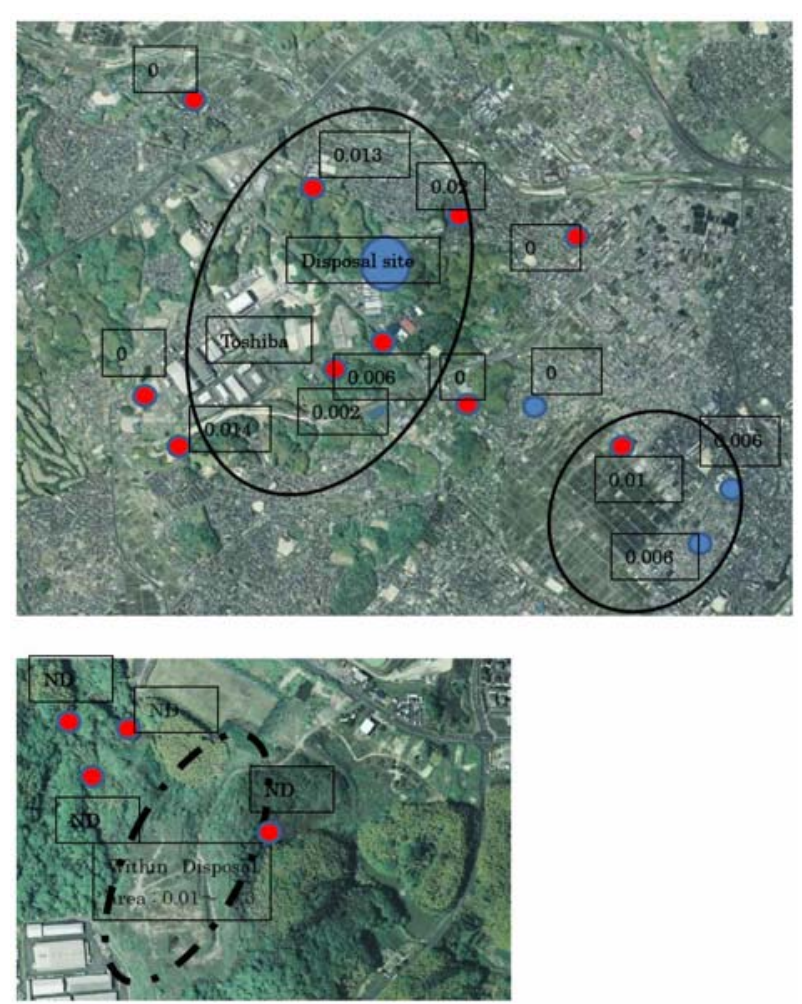

Fig. 3 Arsenic in the water of the investigated area. Unit: mg/L.

\section{Conclusions}

We have investigated the influence of the disposal site on the quality of the ground water in the northern part of Yokkaichi city. We found broad ground water pollution widely in this area, especially near the disposal site. High concentrations of COD, T-N, and 1, 4-dioxane found in the ground water around the disposal 

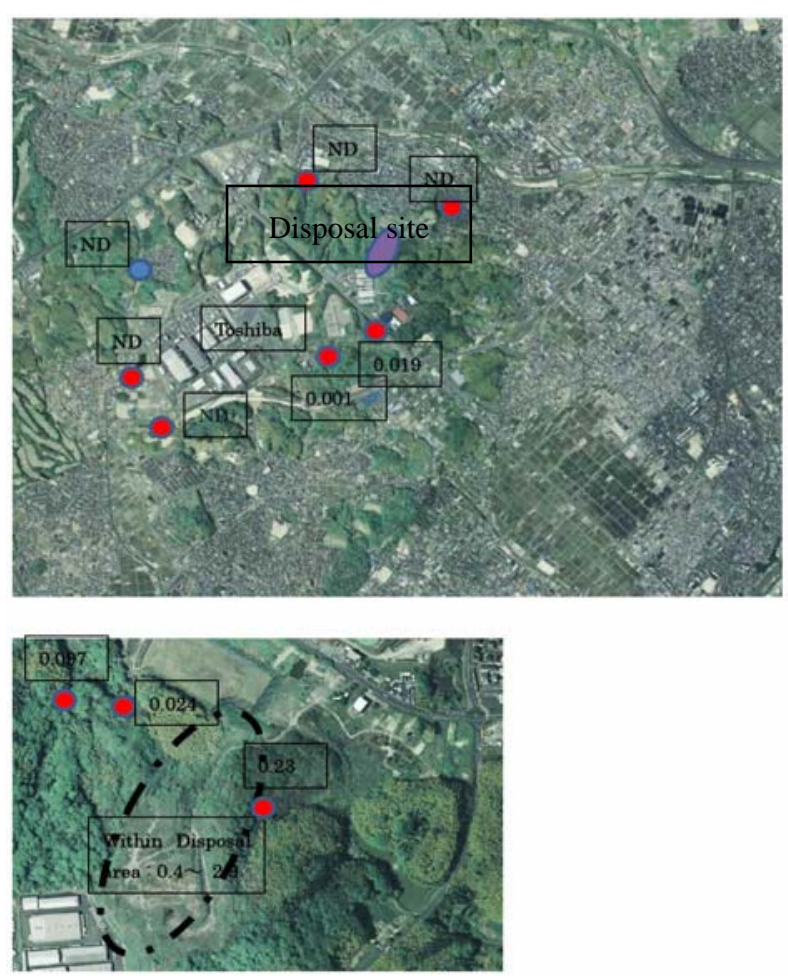

Fig. 4 1, 4-Dioxane in the water of the investigated area (investigation: 9th May 2011).

Unit: mg/L.

site are suggesting an elution of these pollutants from disposal site. However, some pollutants such as arsenic, phosphorus, D-Fe, D-Mn are not considered to be caused by the landfill site directly, and more detailed investigations should be carried out in order to identify the causal relationship between the disposal site and the presence of pollutants [12].

\section{References}

[1] Kayoko, A. 2008. "The Buildup of the Illegal Dump of Industrial Waste in the Ohyachi-Heizu District, Yokkaichi City, Based on the Information Released by Mie Prefecture." Yokkaichi University Journal of Environmental and Information Science 11 (2): 113-36. (in Japanese)

[2] Kayoko, A., Masaaki, T., Mikihiro, I., and Yukimasa, T. 2006. "History and Residential Movement on Illegal Disposal of Industrial Waste in Oyachi-Heizu Area.” In
Proceedings of the 17th Annual Conference of the Japan Society of Waste Management Experts, 95-7. (in Japanese)

[3] Masaaki, T., Kayoko, A., Mikihiro, I., and Yukimasa, T. 2008. "Ground Water and Soil Pollution Near Ohyachi-Heizu Waste Disposal Site.” Yokkaichi University Journal of Environmental and Information Science 11 (2): 27-31.

[4] Masaaki, T., Kayoko, A., Mikihiro, I., and Yukimasa, T. 2009. "Ground Water Pollution in Yokkaichishi Tomida Area.” Yokkaichi University Journal of Environmental and Information Science 12 (2): 39-42. (in Japanese)

[5] Masaaki, T., Kayoko, A., Mikihiro, I., Yukimasa, T., and Peng, G. 2010. "Ground Water Pollution in Oyachi-Heizu District of Yokkaichi City.” Yokkaichi University Journal of Environmental and Information Science 14 (1): 41-8. (in Japanese)

[6] Anzensei, C. S. K. 2011. Matters of the Yokkaichi Ohyachi-Heizu Disposal Site, Mie Prefecture Risk Hyouka-Hyou 2nd version. A survey report. (in Japanese)

[7] Yahoo Aerial Photograph. Accessed May 22, 2012. http://maps.loco.yahoo.co.jp/about.html.

[8] Anzensei, C. S. K. 2006. Ohyachi-Heizu Illegal Waste Disposal Matter, No. 1. Mie prefecture report. (in Japanese)

[9] Masaaki, T., Kayoko, A., Mikihiro, I., and Peng, G. 2009. "A simple Method for Determining Trace Amount of Arsenic in Ground Water with a Detector Tube System.” Yokkaichi University Journal of Environmental and Information Science 13 (1): 95-100. (in Japanese)

[10] Takemoto, Y., Takahashi, M., Kayoko, A., Mikihiro, I., and Guo, P. 2011. "Ground Water Pollution around the Oyachi-Heizu District of Yokkaichi City.” In Proceedings of the First International Conference on Geotechnique, Construction Material and Environment, 21-3.

[11] Mikihiro, I., Masaaki, T., Kayoko, A., and Yukimasa, T. 2009. "Visualization of Elution Tests and Ground Water Pollution of the Disposal Field in Ohyachi-Heize, Yokkaichi, Based on the Report of Mie Prefecture.” Yokkaichi University Journal of Environmental and Information Science 13 (1): 11-23. (in Japanese)

[12] Masaaki, T., Yukimasa, T., Kayoko, A., Mikihiro, I., and Peng, G. 2012. "Ground Water Pollution around the Oyachi-Heizu District of Yokkaichi City.” Yokkaichi University Journal of Environmental and Information Science 15 (2): 83-9. 